\title{
CONTRA O FEBEAPÁ
}

Marilena Chauí

(USP)

Good morning... thanks for the kind invitation. At first I thought I should talk about Brazilian's philosophers in the public sphere but eventually I realized it would be a bit tacky because I would risk not to mention many names and hurt many people. Then I asked myself what actually I should do, what should be the good question to address here and now. What should be our question? And then, suddenly I said to myself: "Oh hell! The answer is right in front of me! "Tupy or not tupy? This is the question!". Dear Oswald de Andrade, thank you. Vamos, pois, ao que interessa colegas.

Eu queria começar me referindo ao Febeapá. Os mais jovens talvez não saibam o que seja o Febeapá... Durante a ditadura, Sérgio Porto, que se autodenominava Stanislaw Ponte Preta, escrevia uma coluna em jornais que, a seguir, foram reunidas em um livro que trazia como título Febeapá. Festival de Besteiras que Assola o País. Então é do Febeapá que eu quero falar um pouco e vou ilustrá-lo inicialmente com duas pequenas crônicas.

\section{Breve crônica escolar}

A professora de Filosofia, Maria Luiza, deu como lição de casa aos seus alunos do ensino médio uma pesquisa sobre a ideia de alma. Para ajudá-los a iniciar o trabalho, distribuiu um pequeno texto em que encontrariam alguns dos nomes de filósofos cujas obras versam sobre o tema proposto.

$\mathrm{Na}$ semana seguinte, ao receber os trabalhos e iniciar a correção, foi tomada por um acesso de fúria que a fez interromper a leitura ao chegar ao décimo trabalho.

Pela manhã, entrou na sala de aula, encarou a classe, tomou um dos textos e iniciou a leitura em voz alta: 
“O filósofo alemão Emanuel Kant declarou que é impossível conhecer o que é a alma humana, porque não podemos conhecer coisas imateriais. Sua opinião, entretanto, foi refutada pelo filósofo holandês Benedito Espinosa, que afirmou que podemos conhecer a alma humana e que ela é a ideia que temos de nosso corpo. Porém, os dois filósofos mencionados foram criticados e refutados pelo filósofo grego Aristóteles, que distinguiu entre três tipos de almas: a vegetativa, a sensitiva e a intelectiva."

A professora Maria Luiza dirigiu-se à classe:

- Este é um entre os vários trabalhos que li. Todos dizem, mais ou menos, as mesmas barbaridades. De onde vocês tiraram tamanha bobagem? Como podem supor que Aristóteles, que viveu no século III a.C., poderia refutar Kant, que viveu no final do século XVIII, e Espinosa, que viveu no século XVII? E como podem supor que Espinosa teria refutado Kant?

João Pedro, provável autor do trabalho lido, ergueu a mão, pedindo para falar. Permissão concedida:

- Professora, essas coisas estão no texto que a senhora distribuiu como base de nossa pesquisa!

- Você está sonhando, João Pedro?

- Não, professora. Pergunte aos outros.

Depois de ouvir a mesma afirmação por parte dos demais alunos, Maria Luiza apanhou o texto distribuído. E a luz se fez!

De fato, seguindo as exigências da $\mathrm{ABNT}$, o texto trazia à frente do nome de cada filósofo uma data: Kant (1970), Espinosa (1972), Aristóteles (2001).

Talvez a professora Maria Luiza devesse dar nota zero para a ABNT. O que acham?

\section{Breve crônica universitária}

Dois estudantes de pós-graduação em Filosofia, um deles trabalhando sobre a obra de Lyotard e outro sobre a de Lefort, obtiveram da FAPESP bolsasanduíche para realizar pesquisas na França sob a orientação de professores da École Normale Supérieure e da École Pratique des Hautes Études. Terminado o período da bolsa e, de regresso ao Brasil, ambos apresentaram à FAPESP relatórios de pesquisa acompanhados de pareceres dos professores franceses e da orientadora brasileira. O material, porém, foi recusado pela FAPESP sob a alegação de que relatórios e pareceres deveriam ser escritos em inglês.

A orientadora caiu das nuvens: a pesquisa se refere a dois filósofos franceses, o trabalho foi feito na França com professores franceses e traduzidos para o português para entrega do relatório. O que o inglês tem a ver com isso? 
Evidentemente, a orientadora reagiu e o material em português foi aceito pela FAPESP, livrando os estudantes da humilhação a que, atualmente, todos são submetidos com os execráveis "abstracts" colocados nas teses num vocabulário supostamente inglês e numa sintaxe claramente de língua portuguesa, isto é, em língua nenhuma. Como disse Nietszche, a bestice humana não tem limites...

Vou retomar o que foi dito pelos meus colegas, mas a partir de um fato que causou grande alvoroço em São Paulo: a publicação pelos jornais sobre a queda da USP e da UNICAMP no ranking das universidades internacionais. Foi uma grande comoção. Jornais publicaram o fato em grandes manchetes e nossos colegas foram entrevistados para responder à pergunta: "Qual a causa dessa queda?" Os entrevistados explicaram que a causa é "a falta de internacionalização". E a falta de internacionalização, explicaram eles, é o fato de não haver os cursos em inglês para estudantes e professores da Filosofia (por que não de chinês, já que a população chinesa é a maior do planeta e a China faz parte dos BRICs, juntamente com o Brasil?). O reitor da USP, que é um colosso intelectual, está tomando providências, criando cursos de inglês para os professores e os estudantes para que os cursos de graduação e pós-graduação sejam ministrados em inglês, a fim de que eles possam, efetivamente, internacionalizar a USP. Não sei se o reitor da UNICAMP tem esse grau de competência mental, técnica, psíquica, política etc. e se vai tomar a mesma providência ou não. O caso é que, neste momento, essa é a discussão na Universidade de São Paulo. Assim, chegamos a um instante em que o mínimo de bom senso, que Descartes garantiu que nós todos temos, também entra em queda. Diante disso, não há mais nada a fazer senão tomar posição no espaço público.

Ivan tinha me pedido que falasse dos filósofos brasileiros no espaço público. Mas eu não vim falar sobre a nossa presença no espaço público. Vim mobilizá-los a ocupar o espaço público, em nome da Filosofia, contra o Febeapá que nos assola.

Quero começar fazendo duas observações gerais a respeito dos "ranqueamentos" e depois uma observação mais particular.

A primeira observação geral é a seguinte: as universidades no mundo todo são muito diferentes, não só porque elas têm histórias muito diferentes e finalidades diferentes, mas porque elas não cobrem o mesmo número de áreas. Algumas, por exemplo, não têm humanidades, outras não têm pesquisa científica (na Alemanha, a pesquisa cientifica não é feita nas universidades, ela é feita no Instituto Planck; na França a pesquisa cientifica não é feita pela universidade, é feita pelo CNRS). Portanto, quando alguém for "ranquear" 
universidades pela pesquisa científica, vai fazer besteira porque vai exigir de algumas universidades a "quota" (Marx ficaria encantado com o vocabulário da mercadoria na avaliação universitária!) de pesquisa científica que não faz parte da história acadêmica, cultural e de pensamento dessas universidades.

Minha segunda observação geral se refere ao fato de que há universidades muito especializadas, com um foco muito preciso, como, por exemplo, a London School of Economics ou a Science Politique, na França. E não se pode exigir delas todas as áreas de ensino e pesquisa sem desfigurá-las e destruir seus propósitos.

Então, nos dois casos (o da pesquisa científica feita em centros fora das universidades e o da especialização de algumas universidades), o que acontece? Você procura na lista de avaliação o lugar ocupado por elas e elas não estão na lista. Não existem. São nada. Por quê? Porque os critérios são cretinos. São critérios que homogeneízam. Não universalizam. Você não pode homogeneizar a diferença. Estandardizar é pretender homogeneizar o diferente, reduzir a pluralidade a uma unidade abstrata e fictícia, isto é, ter uma visão administrativa e mercantil do conhecimento - ou, como insistiram os frankfurtianos, operar com a forma capitalista da troca de equivalentes.

Aliás, é muito interessante observar os critérios empregados para "ranquear". Examinei várias empresas de "ranqueamento" (pois são serviços comerciais realizados por empresas privadas) e os critérios são invariavelmente os mesmos: $30 \%$ para docência, $30 \%$ para pesquisa, $30 \%$ para citações... Eu achei interessantíssimo! 30\% para citações! Citação vale o mesmo que a docência e a pesquisa! Vendo esse critério entendi um tipo de e-mail, muito engraçado, que eu recebo sempre e nunca havia entendido... São e-mails que vêm de empresas que se oferecem para fazer levantamento das minhas citações. Na primeira vez que eu recebi um negócio desses, eu achei que fosse uma piada de mau gosto, que alguém quisesse fazer uma brincadeira sem graça comigo. Depois descobri que há, de fato, empresas para fazer contagem de citação! É uma capitalização da pesquisa! Você paga uma empresa para poder entrar no "ranking”... Gente!... não pode! Não pode! É inaceitável que o pensamento seja submetido a tamanha ofensa! Voltando aos critérios: para chegar aos 100\%, acrescentam-se aos três 30\% de docência, pesquisa e citação, mais $7,5 \%$ para medir a internacionalização (internacionalização significa: recepção de alunos e professores estrangeiros e falar inglês), e mais 2,5\% para medir a inovação industrial. Eu fiquei me perguntando: como as empresas de "ranqueamento" chegaram ao 0,5 para internacionalização e para inovação industrial? Mas sobretudo fiquei me perguntando, no caso da Filosofia, qual seria a nossa contribuição para a inovação industrial. Eu pensei, pensei, 
pensei e concluí que, como estamos na era da informação, do ciberespaço e da cibercultura, a Filosofia pode dar uma contribuição industrial maravilhosa! Ela pode permitir o desenvolvimento industrial da ideia de espírito. Como vocês sabem, os ideólogos e defensores do ciberespaço se referem a ele como espaço desincorporado e espiritual, possibilidade de nos transformarmos em seres de pura luz, livres da brutalidade e do caos próprios de nossos corpos, livres do espaço e do tempo, novos anjos de um novo paraíso terrestre no qual, evidentemente, não haverá morte porque podemos fazer o download de nossas mentes para computadores e, transcendendo a materialidade, viver para sempre no espaço digital. A Filosofia pode retomar e reelaborar com maior precisão a figura do espírito desencarnado, na sua pureza, luminosidade e imortalidade, e fornecer essa ideia para a indústria de computadores. E, com isso, subir no "ranking"!

Mas de onde vêm os critérios? Há um professor, Simon Nerguson, especialista em "ranqueamento", que fez avaliações de praticamente todas as universidades do planeta e cujo último contrato foi feito com uma empresa chinesa, a Shanghai Jiao Tong University Academic Ranking of World Universities. Quero tomar algumas observações feitas pelo professor Nerguson.

Primeira observação: as universidades latino-americanas estão em grande desvantagem, nesse processo de "ranqueamento" global, por vários motivos: o primeiro é o viés da publicação em inglês. Nerguson recomenda, ao contrário, que a avaliação enfatize a regionalização ou seja, "ranqueamentos" regionais respeitando a língua de cada país.

Segunda observação: cada um de nós valoriza a sua própria história, sua própria cultura; quando a comparação, para um "ranqueamento" global em educação superior, é feita com base numa perspectiva monocultural, impõe-se a toda a diversidade mundial das universidades um padrão uniforme que não corresponde à sua realidade histórica e cultural e, pior do que isso, a história, a cultura, a economia, o conjunto de instituições singulares se tornam uma fonte de desvantagem. Assim, aquilo que uma universidade tem de próprio e singular se transforma numa desvantagem para sua avaliação.

Terceira observação de Nerguson: uma monocultura universitária destrói qualquer possibilidade de classificação; ela é destrutiva, não produz uma classificação. Diz ele: "estarão salvos aqueles que nasceram em Oxford ou em Harvard". Em caso contrário, está todo mundo perdido. Por exemplo, diz ele, a USP é a oitava universidade produtora de ciência em inglês tendo, portanto, uma presença muito forte na economia das listagens; entretanto, ela é muito pouco citada porque os papers que não são em inglês estão incluídos nas 
publicações e atrapalham a contagem. Em outras palavras, o que for escrito em português não conta e, pior, atrapalha.

Quarta observação: a metodologia usada - os tais 30\%, 7,5 e 2,5 - nessas listagens não é suficientemente clara e robusta para permitir dados que validem as humanidades. De fato, diz Nerguson, as multilinguagens nas humanidades não podem de forma alguma ser reduzidas a medidas universais, como papers em revistas de genética. Não se pode fazer isso com as humanidades. As virtudes das humanidades residem, sobretudo, na sua diversidade, na sua heterogeneidade, na sua incomensurabilidade.

Isso é o que afirma o homem que faz os rankings, dizendo que os critérios não servem para as humanidades, não servem para a América Latina, não servem para a Filosofia. Eu me vali dele porque sou uma pessoa muito estabanada que sai aí pelo espaço público a berrar, só por causa da minha paixão. Eu resolvi que não iria berrar só com a minha paixão, eu iria fundamentar a minha paixão em dados convincentes. Esse é o homem que faz o ranking e ele diz que o ranking não presta.

Ivan Domingues: repete o nome dele aqui.

Marilena Chauí: O nome dele é Simon Nerguson. (pode olhar em $<$ http// www.universityworldnews.com $>$. Improving Latin American global ranking. 10 jun. 2012).

Fiz todas essas observações, porque quero enfatizar o seguinte: o Febeapá que se anuncia é a ideia dos cursos de graduação e pós-graduação em inglês, das revistas em inglês, de teses em inglês, de congressos, colóquios e seminários em inglês. Quero reafirmar o que disse Guido quando salienta a diferença entre o grego da koiné e o latim do império romano e o inglês: a koiné e o latim eram as únicas línguas cultas (isto é, que possuíam gramática, retórica, ortografia fixada etc.) a que todos podiam ter acesso (e não um privilégio das castas sacerdotais e suas linguagens secretas), o que de maneira nenhuma se aplica ao inglês no conjunto das demais línguas contemporâneas. Não há justificativa cultural para declarar a hegemonia do inglês.

Especificamente, no caso da Filosofia, quero lembrar, sobretudo aos mais jovens, que, nos últimos cinquenta anos, houve um esforço monumental de todos que fazem Filosofia no Brasil para criar um vocabulário filosófico em português, para criar uma linguagem filosófica em português, que não existia. Sejam os nossos escritos, sejam nossas traduções, sejam as pós-graduações, todo o esforço foi dirigido à ideia de criar um trabalho de Filosofia em língua portuguesa. É isto que, agora, querem por abaixo, no instante em que se confunde o universal com a internacionalização e a internacionalização com o homogêneo. Nossa universalidade está justamente em sermos capazes de 
dizer o universal por meio do particular de uma língua. Essa capacidade é exatamente um gesto filosófico: o de saber como estabelecer a relação entre o universal e o particular... E não confundir o particular com o dado empírico, nem o universal com a homogeneidade do universo administrado, do mundo da equivalência das mercadorias. Por ser a capacidade para articular $o$ universal e o particular, é um ato filosófico de nossa parte exigir a Filosofia falada e escrita em português. Cada um de nós é capaz de lidar com as outras línguas. Nós já demos provas disso. Agora é a hora dos que falam outras línguas lidarem conosco. Lidarem com o que nós escrevemos, com o que nós produzimos.

Gente, não foi pouco! Nós criamos uma língua filosófica no Brasil e é esse patrimônio que vai ser posto fora, por causa do besteirol deste inglês. Porque digo que é um besteirol? Vamos doravante ter cursos de história do Brasil em inglês? Literatura portuguesa em inglês? Literatura brasileira em inglês? Ensinar grego e latim em inglês? Mas o grau da estupidez e da tolice vai até lá? E essa é a ideia que reaparece no caso da Filosofia.

Eu gostaria de dar um pequeno exemplo da tragédia dos jovens, porque são eles, coitados, que foram jogados nessa fogueira. Alguns estão contentinhos... Estão alegrinhos, vão fazer trabalhos em inglês, vão falar inglês, vão publicar em inglês, acham que as portas do mundo se abrirão (como nos comerciais de televisão sobre o aprendizado do inglês por Internet - sucesso garantido na empresa e no amor).

O exemplo que eu quero dar é o seguinte. Todo mundo conhece o poema do Chico Buarque, "Construção". Imaginemos uma jovem que, no curso de Estética, decide escrever um ensaio sobre esse poema. Há nele coisas extraordinárias, a começar pelo uso feito por Chico da rima escura e deslocada, que é uma das rimas mais difíceis em português; ele faz isso escolhendo as palavras única/único, última/último, único/público; ele trabalha também um outro conjunto dificílimo de palavras feito com o encontro consonantal tr: trôpego/tropeçou/ contramão/trânsito/atrapalhando; e introduz as palavras "mágico" e "tijolo", que sintetizam fonicamente as palavras "único", "público" e "trânsito" - "tijolo por tijolo num desenho mágico". Ora, a maneira como Chico desloca no interior do poema as palavras único/única/ último/ última/ trôpego/ trânsito/ contramão faz com que o poema que fala sobre a construção de um edifício seja ele próprio uma construção, cada palavra é "tijolo por tijolo num desenho mágico" - Chico canta, de uma só vez, o pedreiro e o poeta. Construção é o que fazem o pedreiro e o poeta. A estudante escreve o ensaio. E aí, entusiasmado, o jovem professor, diz: "Está ótimo! Agora, traduz para o inglês, para publicar... [risos] Ah... brick by brick. He fell on the street. Acabou! 
É a ruína do pensamento! É a ruína da linguagem! É a ruína das artes! É com isso que estamos sendo estupidamente coniventes.

Então, a minha função aqui, hoje, em nome do patrono da Filosofia, que lutou contra a tolice humana, é propor uma mobilização nacional dos filósofos contra a morte do pensamento, a morte da Filosofia, no Brasil.

Essa mobilização contra o Febeapá pode tomar várias formas: pode tomar a forma do ataque direto, como estamos fazendo aqui, mas também pode tomar a forma da chefia Guarani. Todos aqui conhecem a chefia Guarani, não é? Como vocês se lembram, a sociedade Guarani impediu a transcendência do poder, que o poder se separasse da sociedade. Entre as várias medidas que ela tomou para isso, uma delas foi a seguinte: toda as tardes, na hora do crepúsculo, o chefe subia numa pequena elevação e pronunciava o discurso do poder: eu sou extraordinário, eu sou maravilhoso, eu fiz isso, eu fiz aquilo, eu dei ordem para que fizessem aquilo, eu quero que façamos uma guerra... Enquanto ele falava, a tribo continuava seus afazeres, suas conversas, como se o chefe não estivesse ali nem estivesse falando. Ele fala, para não ser escutado, porque, se alguém o escutar e o levar a sério, permite que surja o poder separado da tribo, o poder do Estado. Proponho que façamos como os guaranis: as agências falam, os reitores falam e a gente não escuta. E continua fazendo aquilo que tem que fazer e gosta de fazer. Ou nós podemos tomar uma atitude, como a de La Boétie contra a servidão voluntária: eles querem que a gente faça isso, não faremos. O que farão eles? Cairão. Obrigada!

\section{[aplausos]}

